This item was submitted to Loughborough's Research Repository by the author.

Items in Figshare are protected by copyright, with all rights reserved, unless otherwise indicated.

\title{
Design for environment analyses applied to rapid manufacturing
}

PLEASE CITE THE PUBLISHED VERSION

PUBLISHER

(C) Professional Engineering Publishing

LICENCE

CC BY-NC-ND 4.0

\section{REPOSITORY RECORD}

Hopkinson, Neil, Y. Gao, and D.J. McAfee. 2019. "Design for Environment Analyses Applied to Rapid Manufacturing”. figshare. https://hdl.handle.net/2134/3560. 
This item was submitted to Loughborough's Institutional Repository by the author and is made available under the following Creative Commons Licence conditions.

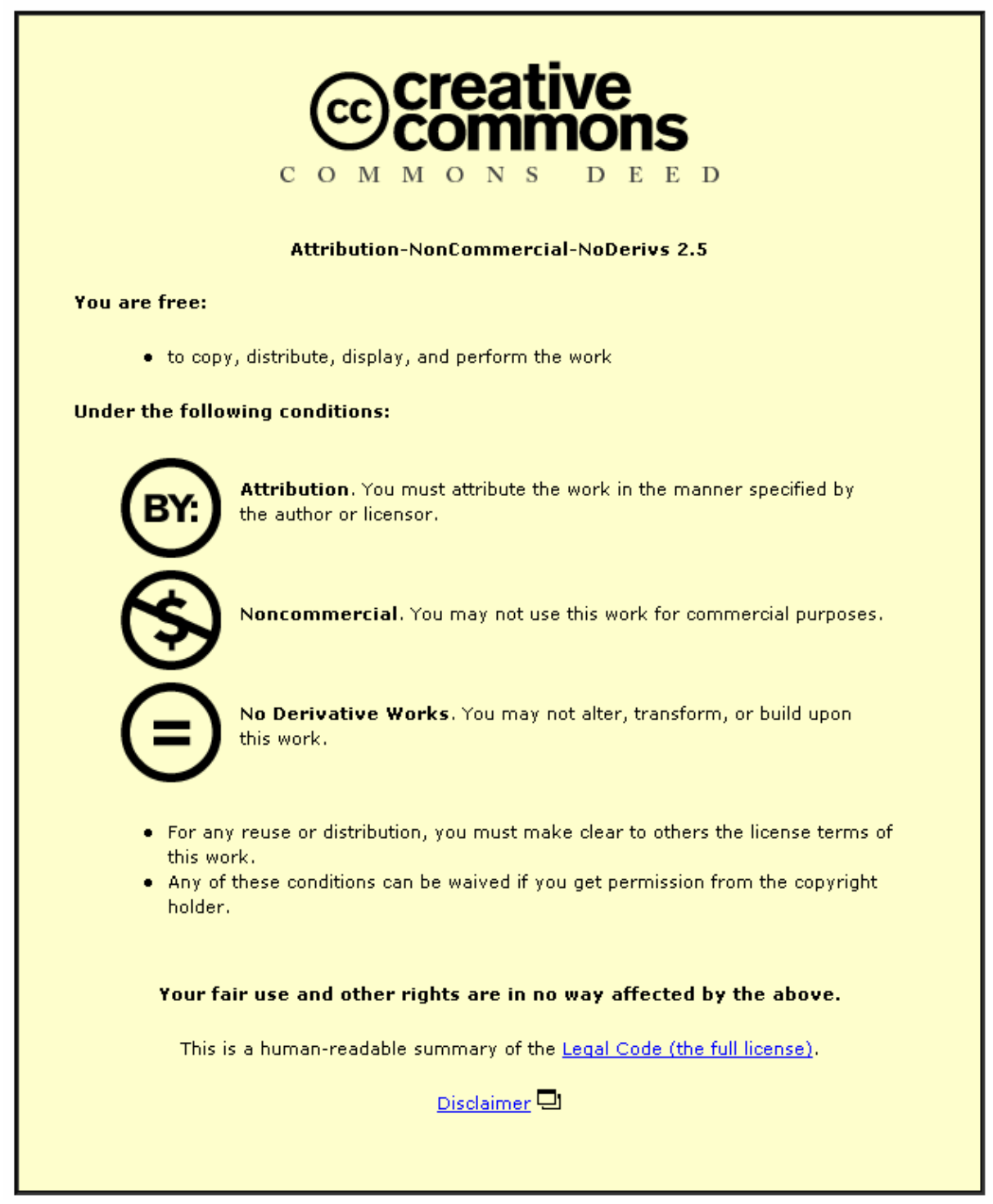

For the full text of this licence, please go to: http://creativecommons.org/licenses/by-nc-nd/2.5/ 


\title{
Design for environment analyses applied to rapid manufacturing
}

\author{
N Hopkinson ${ }^{1 *}$, Y Gao $^{1}$, and D J McAfee ${ }^{2}$ \\ ${ }^{1}$ Wolfson School of Mechanical and Manufacturing Engineering, University of Loughborough, Loughborough, \\ Leicestershire, UK \\ ${ }^{2}$ Jaguar Cars Limited, Abbey Road, Whitley, Coventry, UK
}

The manuscript was received on 10 March 2006 and was accepted after revision for publication on 19 June 2006.

DOI: 10.1243/09544070JAUTO309

\begin{abstract}
This paper explores the potential to combine rapid manufacturing (RM) technologies and design for environment (DFE) software with an automotive application. The work focuses on the redesign of a door handle assembly for the Jaguar XJ Saloon. The original 11-piece assembly, comprising eight different materials, was subject to a redesign with an RM technology in mind as the method for final manufacture. In this case the suggested method for manufacture was selective laser sintering (SLS). The design freedoms afforded by the SLS process had a profound effect on the potential to redesign the product. Two different redesigns were proposed, and these, along with the original design, were subjected to analyses of environmental burden and financial profits/costs for end-of-life recycling and reuse using Boothroyd Dewhurst DFE software. The first redesign incorporated the entire assembly as a single prefabricated unit and consequently rendered a DFE analysis impossible. The second redesign was a four-piece assembly retaining three metallic components from the original product and, when subjected to the DFE analysis, showed a significant reduction in environmental burden and cost for disassembly. The surface finish of the SLS parts proved to be inadequate for visual components on a luxury car, but the potential to apply RM for applications with less stringent aesthetic requirements remains.
\end{abstract}

Keywords: rapid manufacturing, rapid prototyping, selective laser sintering, design for environment

\section{INTRODUCTION}

Rapid manufacturing (RM) has been recognized as a family of advanced manufacturing techniques that may produce components with complex geometries that cannot be made by conventional manufacturing processes. The design freedom allowed by RM may simplify end-of-life disassembly, thus reducing dismantling time and associated costs.

The concept of design for environment (DFE) has harmonized design concerns with environmental issues. Boothroyd Dewhurst DFE software may be used to analyse designs in terms of their cost and ease of disassembly along with environmental impacts.

\footnotetext{
* Corresponding author: Wolfson School of Mechanical and Manufacturing Engineering, University of Loughborough, Abbey Road, Loughborough, Leicestershire LE11 3TU, UK. email: N.Hopkinson@lboro.ac.uk
}

More attention, especially in industrialized countries, has to be paid to the environmental effects of products from both a legislative and commercial perspective. Companies need to implement strategies that reduce the environmental impacts of their products and services. If companies fail to address environmental performance in product design and development, they will find themselves becoming less competitive and contravening laws.

The aims of the present paper are to apply product redesign with environmental considerations to RM. An automotive application has been selected in light of the European Union End-of-Life Vehicle Directive (Directive 2000/53/EC). Firstly, the background reviews recent research concerning RM and DFE; this includes an introduction to Boothroyd Dewhurst DFE software as an assessment tool in order to evaluate designs using materials, energy, and toxic emissions (MET) scores and an associated costing method. 
Secondly, the redesign of the Jaguar XJ saloon door handle provided by Jaguar Cars Limited demonstrates the advantages of RM in relation to design freedoms afforded by the SLS process. Thirdly, a DFE comparison of both financial and environmental assessments of the original product and the product redesign is presented. Finally, the conclusions discuss the results and implications of combining RM technologies with DFE approaches, along with some of the broader issues relating to RM.

\section{BACKGROUND}

\subsection{Review of rapid manufacturing}

Rapid manufacturing has been defined as 'the direct production of finished goods from a Rapid Prototyping (RP) device' [1]. RM has evolved from RP technologies and is being used to produce enduse products from three-dimensional modelling digital data so that moulds can be eliminated [2] Currently, there are no machines designed specifically for RM. Nevertheless, some RP systems are being used successfully in RM applications for the production of end-use parts, such as stereolithography (SL) and selective laser sintering (SLS). The use of $\mathrm{RM}$ in the final production process was initially recommended by Dickens in 1999 [3]. Several benefits were identified, such as tool-less manufacturing, great design freedom, and flexible and customeroriented manufacturing. RM, however, also has limitations including low build speed and accuracy, unsatisfactory surface finish, poor repeatability when manufacturing parts, limited variety of materials, and generally poor mechanical properties. In order to overcome these obstacles, current research is mainly focused on new RM processes [4], CAD product design issues [5], material properties [6], and the management of RM [7].

In spite of the fact that RP technologies are very young, RM applications have already been used in many industries in recent years. RM processes are generally best suited to small products with complex geometry and low production volumes, but larger parts and production volumes have proved successful in some cases. Notable examples of RM include the use of SLS to manufacture hearing aids in hundreds of thousands [8], while SLS is also used extensively in the manufacture of fighter jets and Formula 1 race cars [9]. Another high-volume application for parts made by RP technology includes the manufacture of moulds for dental aligners, where volumes over 3 million units per annum are manufactured by stereolithography [10].

\subsection{Outline of design for environment}

Fiksel and Wapman defined design for environment (DFE) as 'the system consideration, during new production and process development, of design issues associated with environmental safety and health over the full product life-cycle' [11]. Environmental impacts may occur at different stages of a product life cycle. However, the environment is not the only consideration when designing a product. DFE intends to integrate 'design for $\mathrm{X}$ ' methodology [12] with environmental issues. Ehrenfeld and Lenox argued that DFE aims to "bridge the gap between two traditionally separate functions: product development and environmental management' [13]. The goal, however, is to "bring these two functions into closer contact and address product life-cycle issues .... DFE provides an opportunity for corporations and governments to recognize environmental harm at the early product development stage, thus avoiding or reducing downstream environmental impacts and costs of associated legislation.

Numerous DFE tools, such as life cycle assessment (LCA) and environmental impact assessment (EIA), have been applied by companies to appraise environmental outcomes. LCA is an analytical tool that specifically assesses the environmental impacts in relation to the whole product life cycle. From a commercial point of view, the best manner of producing environmentally sound products is to reduce both the environmental liabilities and relevant costs. LCA cannot accomplish both individually. The general way is to combine LCA with life cycle cost analysis (LCCA) to assess both the financial and environmental impact of the product. The problem is that it needs an expert to interpret the results and it is time consuming. Boothroyd Dewhurst DFE software, however, is able to assess both environmental effects of the product design and financial effects of its endof-life disassembly. It is easy to use and understand for both designers and engineers.

\subsection{Introduction to Boothroyd Dewhurst DFE software}

Boothroyd Dewhurst DFE software is a good tool to review a design or to highlight redesign improvements in terms of minimizing financial costs and environmental burdens. It is the aim of DFE to produce graphs where financial and MET lines finish as high as possible. To explain the results of the assessment, a sample graph from this software is shown in Fig. 1. The financial line shows the cumulative costs and revenues as disassembly proceeds. The points on the graph stand for a 


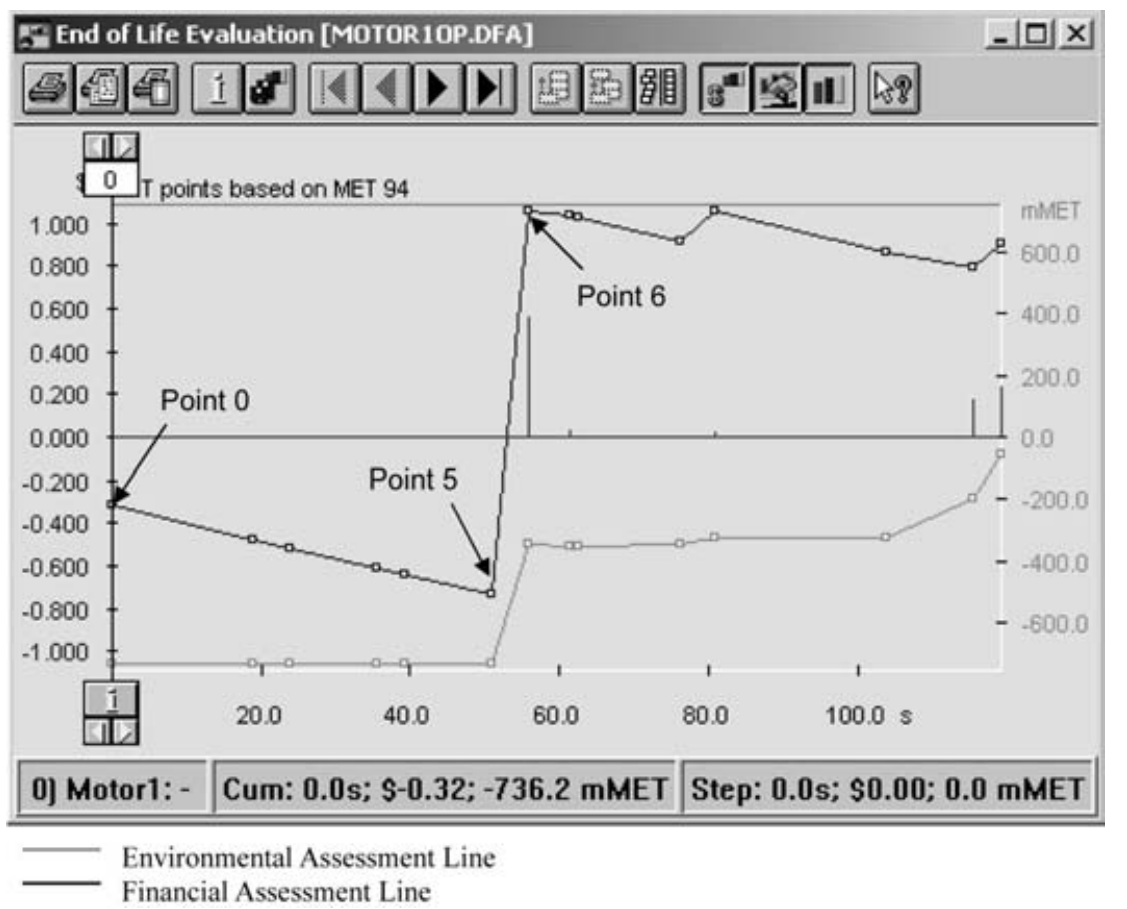

Fig. 1 Sample graph of Boothroyd Dewhurst DFE software

dismantling operation or the removal of an item. When disassembly is stopped at point 6 in Fig. 1, the net profit (left-hand side of the graph) is approxi-

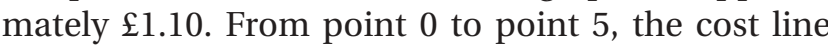
declines gradually and then rises steeply at point 6 . This is because the previous five parts have been recycled and the sixth one has been reused; the returns on recycling are less than the costs of the relevant labour rate, whereas the reuse of a valuable part may achieve a marked financial profit.

The environmental line, also named the MET-score line, shows the cumulative environmental effects determined by both the production process and end-of-life issues when disassembly proceeds. When disassembly is stopped at point 6 in Fig. 1, the MET score (right-hand side of the graph) is -350 mMET. The vertical bars show the negative effects of both the materials and the manufacturing process of the individual item, together with the end-of-life recycling and disposal process. For instance, the longest bar emerged just above point 6 , which indicates that producing this part will create the worst impact. Conversely, if this part is reused or recycled, it will also provide the highest environmental benefit.

The MET scores are similar to those used in conventional LCA and consequently inherit the limitations from LCA scores. However, the MET scores may be used as a guide in terms of selecting alternative materials, easing disassembly, or altering the disassembly sequence. A further limitation with the MET scores is that they are based on a finite set of manufacturing processes and materials. In many cases the actual method and material of manufacture may not be available in the software and a closest fit needs to be selected.

\section{PRODUCT REDESIGN}

Figure 2 shows the front and rear views of the original Jaguar XJ Saloon door handle assembly. Table 1 shows the parts list for the assembly, including parts weight and manufacturing process and material assumed for the DFE analysis. The product comprises 11 different components made from eight different materials. This means that at the end of life, assuming that total reuse for the entire product is not an option, considerable disassembly and separating of parts will be required.

Three-dimensional CAD models of the existing door handle assembly were not available and so twodimensional drawings, along with reverse engineering for curved features, were used to generate threedimensional CAD models for the new designs. CAD modelling via reverse engineering was carried out in six steps.

1. Defining datum and coordinates by any five points on the product - three for the datum plane and two for the datum axis. 


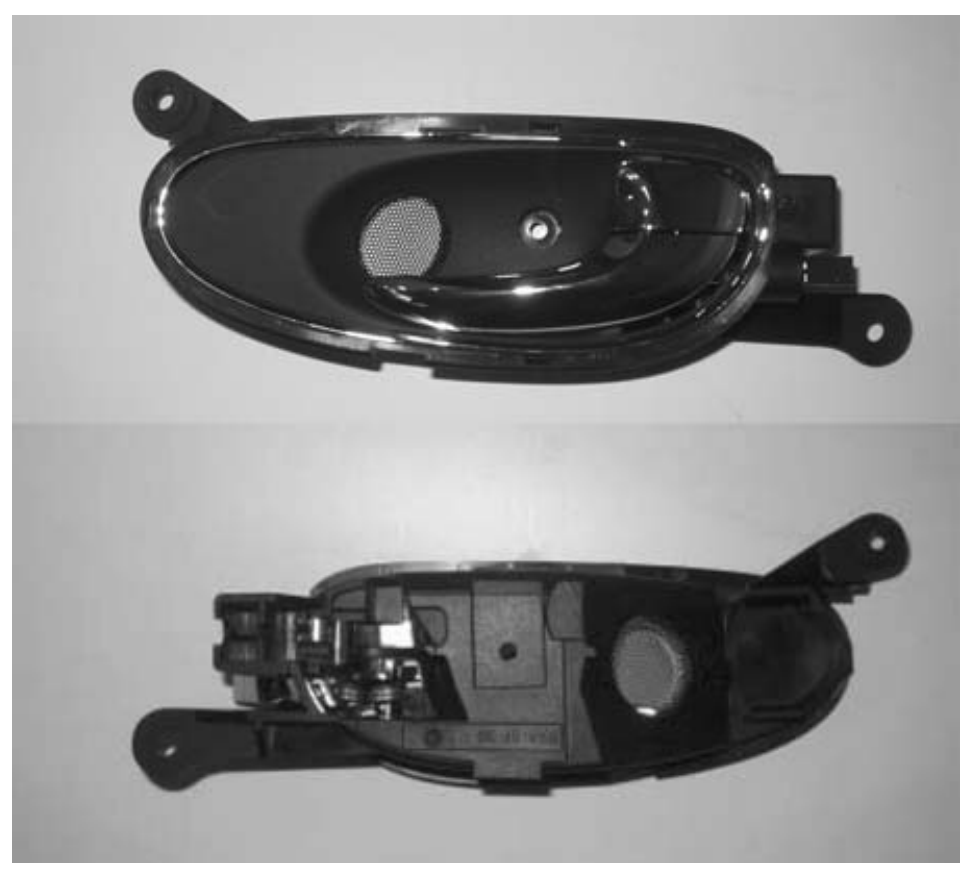

Fig. 2 Front and rear views of the original door handle assembly

2. Drawing the curves that could shape the sample, and depicting points on the sample roughly.

3. Taking the points manually, with automatic recording by the computer.

4. Editing the data so that they can be identified by UG software.

5. Creating relatively smooth curves through Unigraphics three-dimensional software and then outputting them in an IGS format.

6. Inputting the IGS format to Pro-Engineer software, as all modelling work is finished by it.

\subsection{Concept development}

Rather than design a completely new concept, it was decided to minimize overall geometry changes from the original design so that minimal disruption would be caused if a door handle manufactured by SLS could be incorporated into the car. However, the design intention was to eliminate any unnecessary components and reduce the overall part count by amalgamating parts where possible. The rudimentary three-dimensional layout drawings of the housing are shown in Fig. 3.

\subsection{Design proposal I}

This first idea came from the design freedom of RM techniques in so far as they allow any shape created by three-dimensional software to be produced. Without manufacturing constraints, it is possible
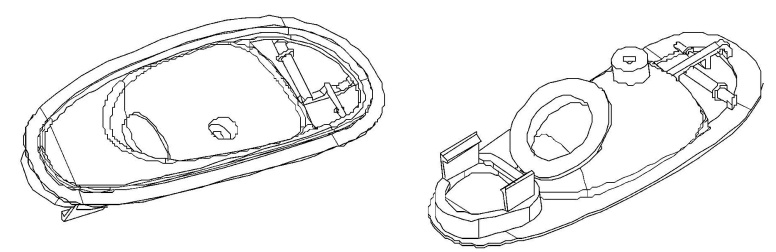

Fig. 3 Conceptual layout drawing of the housing three-dimensional

to combine functions given by 11 parts in one by three-dimensional CAD modeling. It was therefore possible to design the product in the form of a preassembled unit. According to design for assembly (DFA) approaches [12], the best way to improve design efficiency is to separate the assemblies into essential and unessential parts, and then to reduce unessential parts as much as possible. The SLS process creates parts in nylon 12 powder which has good wear resistance. Therefore, the insert release lever (item 7 in Table 1) could be eliminated, as its main function is to prevent the wearing out of both the lock lever and the release lever. The buffer handle (item 11 in Table 1) serves to reduce the restore force of the release lever. It was considered an unessential part and thus could also be eliminated. The functions of the other parts, such as items $2,8,9$, and 10 , could be combined in the housing. A drawing of design idea I is shown in Fig. 4.

The part was built by SLS to verify the feasibility of the design. In order to obtain the best possible 
Table 1 Parts list of the original door handle

\begin{tabular}{|c|c|c|c|c|c|}
\hline Number & Name & Image & Weight (g) & Material & Manufacturing process \\
\hline 1 & Chrome rim $\mathrm{RH}$ & & 11.44 & ABS & $\begin{array}{l}\text { Injection moulding and } \\
\text { chromium plating }\end{array}$ \\
\hline 2 & $\begin{array}{l}\text { ESC moulding RH } \\
\text { non-memory }\end{array}$ & & 91.52 & PA6-GF30 & Injection moulding \\
\hline 3 & Tweeter mesh RH & & 10.77 & Zinc alloy & $\begin{array}{l}\text { Press sheet metal and } \\
\text { painting }\end{array}$ \\
\hline 4 & $\begin{array}{l}\text { Housing handle door } \\
\text { I/S RH }\end{array}$ & & 211.86 & PA6-GF30 & Injection moulding \\
\hline 5 & $\begin{array}{l}\text { Release lever handle } \\
\text { door I/S RH }\end{array}$ & & 265.76 & Zinc & $\begin{array}{l}\text { Die-casting and } \\
\text { chromium plating }\end{array}$ \\
\hline 6 & $\begin{array}{l}\text { Lock lever handle door } \\
\text { I/S RH override }\end{array}$ & & 126.5 & Zinc & $\begin{array}{l}\text { Die-casting and } \\
\text { chromium plating }\end{array}$ \\
\hline 7 & $\begin{array}{l}\text { Insert release lever handle } \\
\text { door I/S RH }\end{array}$ & & 2.42 & POM & Injection moulding \\
\hline 9 & Release lever bolt & & 10.12 & 9SMnPb28K & Machining \\
\hline 10 & Lock lever bolt & & 3.08 & 9SMnPb28K & Machining \\
\hline 11 & Buffer handle & & 0.1 & $\begin{array}{r}\text { EPDM-80 } \\
\text { Shore A }\end{array}$ & Injection moulding \\
\hline
\end{tabular}

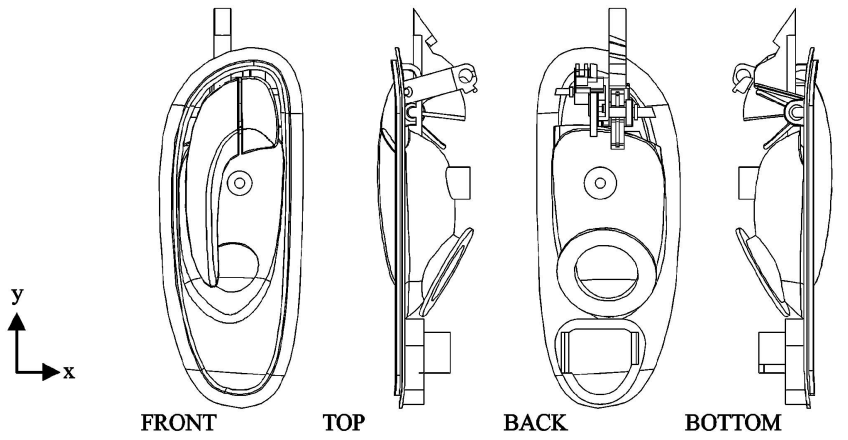

Fig. 4 Assembly layout drawing - two-dimensional surface texture, the effect of build orientation was assessed. This was done by building one part in the orientation shown in the top view in Fig. 4 and another part in the front view as shown in Fig. 4. Once built, the RM parts demonstrated that building the pin and hole on the $X Y$ plane (which is the topview orientation in Fig. 4) achieved a better surface texture than the one rotated $90^{\circ}$ in the $Y$ axis. The SLS parts also revealed three design flaws.

1. The clip gave a stiff response and did not exhibit sufficient memory. 
2. A $0.3 \mathrm{~mm}$ clearance between holes and pins was not sufficient for smooth rotation.

3. With a diameter of $1.0 \mathrm{~mm}$, not all speaker holes were fully formed.

To improve the design, the clearance between pins and holes was modified from 0.3 to $0.6 \mathrm{~mm}$, the diameter of the speaker holes was increased from 1.0 to $1.5 \mathrm{~mm}$, and the distance between the holes was changed from 1.5 to $2.0 \mathrm{~mm}$. Additionally, four concepts of spring mechanism were proposed. Incorporating these changes, four updated designs (one for each spring mechanism) were manufactured by SLS. Assessing these four components, it was found that the design using a $4 \mathrm{~mm}$ spring diameter achieved the best function and that the changes to pin/hole clearance and speaker holes had been successful. The final design solution with a $4 \mathrm{~mm}$ spring is shown in Fig. 5.

\subsection{Design proposal II}

While the design described above functioned adequately, it would not be acceptable in a Jaguar car in terms of its appearance. In order to improve the appearance of the product, a design compromise was proposed which included the three visual metallic components from the original product, i.e. release lever, lock lever, and rim. As with the original unit, all other features were combined in the housing so that design considerations could be focused on the sequence of the assembly and end-of-life disassembly. The SLS main component was also painted to improve the appearance, although pigmented powders for SLS can be produced if required for RM applications. The images of the final design solution, including metal components and a painted SLS body, are shown in Fig. 6.

\section{RESULTS OF BOOTHROYD DEWHURST DFE ASSESSMENT}

\subsection{Original design}

Table 2 shows the disassembly sequence for the original design. Figure 7 shows the MET point and cost graphs for the original product generated by the DFE software and shows that the total disassembly time is approximately $140 \mathrm{~s}$. Without conducting the disassembly operation, the environmental score is -1000 mMET. As no take-back cost was set in this case, the financial loss was nearly zero. If the door handle had been fully dismantled, the financial cost would have been $-£ 1.00$ and the MET score nearly zero. Three vertical bars emerge above points 2, 3, and 5 , which means that the reuse of three parts the engineered structural composite (ESC) moulding, the release lever, and the lock lever - can achieve the

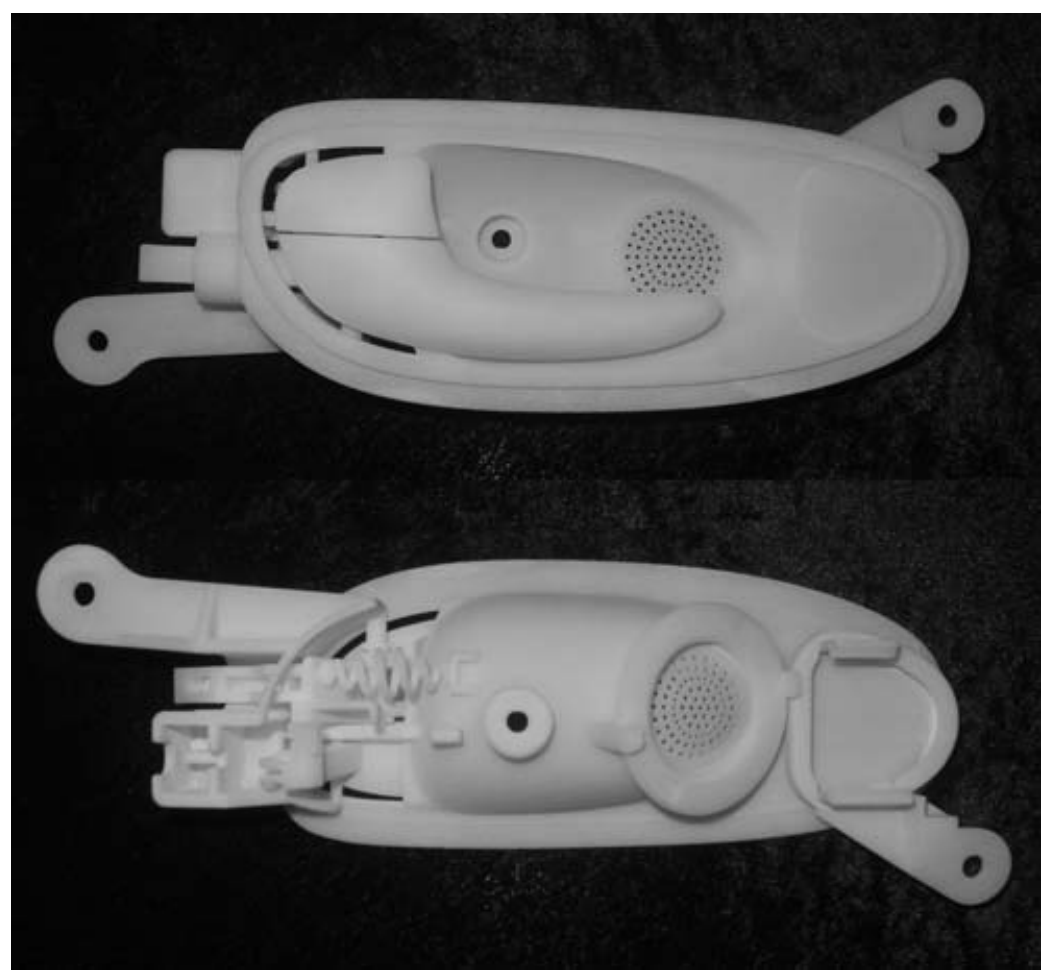

Fig. 5 Front and rear views of design idea I 


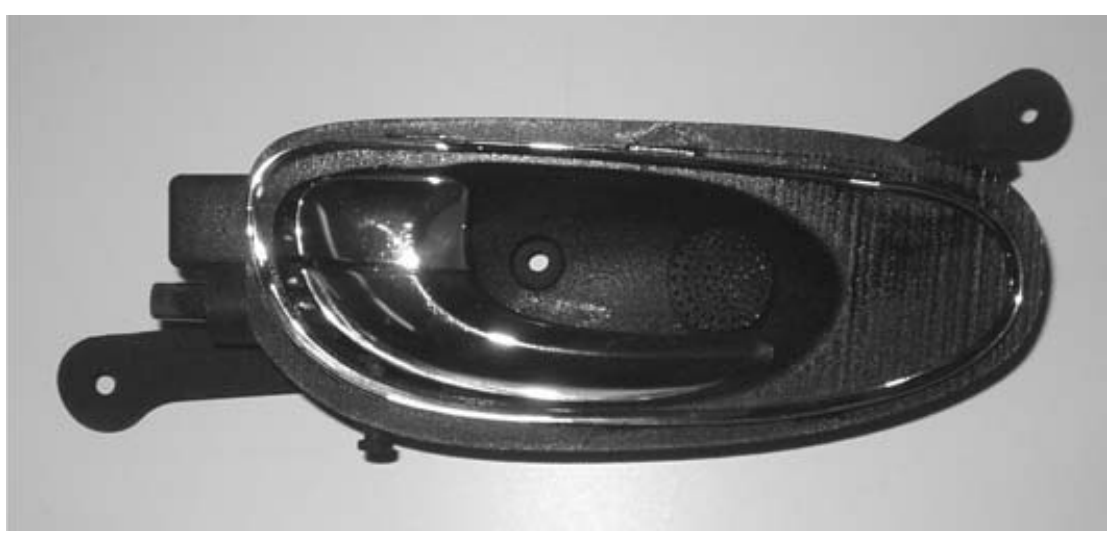

Fig. 6 Photograph of the four-component assembly made by SLS

Table 2 Disassembly sequence for the original design

\begin{tabular}{cll}
\hline Step & Process & Reuse or recycle? \\
\hline 1 & Remove the release lever pin & Recycle \\
2 & Unfasten the snap fit on the ESC moulding & Recycle \\
3 & Remove the release lever & Reuse \\
4 & Unfasten and remove the lock lever bolt & Recycle \\
5 & Remove the lock lever override & Reuse \\
6 & Remove the spring release lever & Recycle \\
7 & Unfasten and remove the chrome rim with screw driver & Recycle \\
8 & Remove the insert release lever & Recycle \\
9 & Remove the tweeter mesh & Recycle \\
10 & Remove the buffer & Recycle \\
11 & Remove the housing & Recycle \\
12 & Remove the release lever pin & Recycle \\
\hline
\end{tabular}

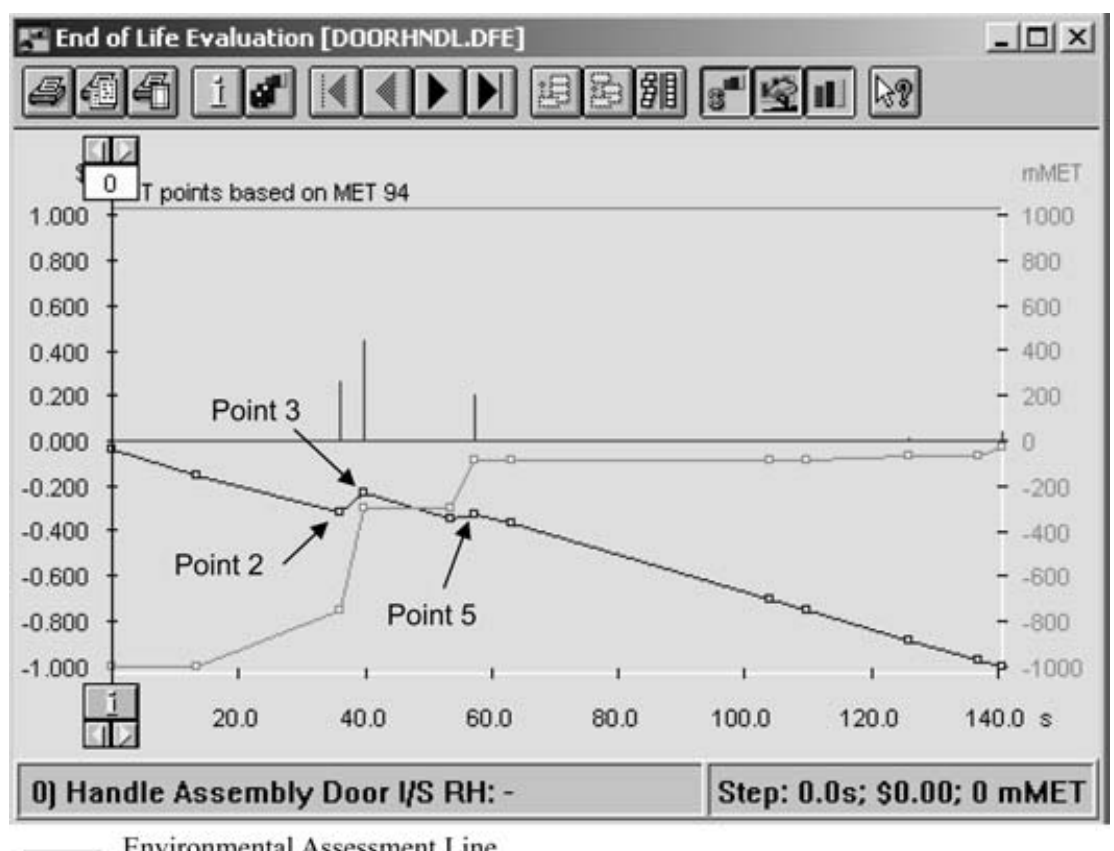

Environmental Assessment Line

Financial Assessment Line

Fig. 7 Boothroyd Dewhurst DFE assessment graph of the original product 
clearest environmental benefits. The optimal option is for the disassembly sequence to be stopped at point 5 , which is the removal of the lock lever. This is because the subsequent steps have cost implications but achieve negligible MET gain.

\subsection{Design idea I}

It was not possible to generate a DFE graph for design idea I as it could not be disassembled. It was assumed that the entire product would be recycled and, as it was manufactured from a single material, no separation of parts would be required.

\subsection{Design idea II}

Figure 8 shows an exploded view of the four components that comprised design idea II. Table 3 shows the disassembly sequence for design idea II.

The assessment shown in Fig. 9 is based on the same assumption as the evaluation shown in Fig. 7 that the profits of reusing the two zinc die-casting parts are $£ 0.10$ (release lever) and $£ 0.05$ (lock lever). According to the graph in Fig. 9, it takes $40 \mathrm{~s}$ to remove all parts; the point of maximum profit is attained when disassembly is stopped at point 2 . With the MET scores from -600 to -100 mMET, the environmental line increases steadily from point 0 to point 2 , and then gradually to zero. It means that the removal of the two zinc parts can achieve the maximum financial profits with relatively low environmentally negative effects. The vertical bars tell the same story: reusing the two parts will increase the environmental benefits.

\subsection{Comparisons between the original product and the redesigns}

The most significant result drawn from this study is the fact that the first redesign, which made maximum use of the design freedom offered by SLS, could not be subjected to a DFE analysis. The design freedom that allows a multipart assembly to be built from a single component in a single material may have profound effects on future design for disassembly/ environment approaches.

The comparison of both the financial and environmental impacts of the original product and the fourcomponent redesign idea is shown in Fig. 10. With the original product, the cost of dismantling all eleven parts is approximately $£ 1.00$, taking $140 \mathrm{~s}$. However, with the four-component design idea it takes $40 \mathrm{~s}$ at neutral cost and with zero environmental impact. The financial line for the four-component design shows that the maximum profit is achieved by stopping disassembly at step 2 .

\section{CONCLUSIONS}

The results from the DFE analyses indicated that parts designed to be made by an RM process such as SLS may achieve significant benefits in terms of reduced

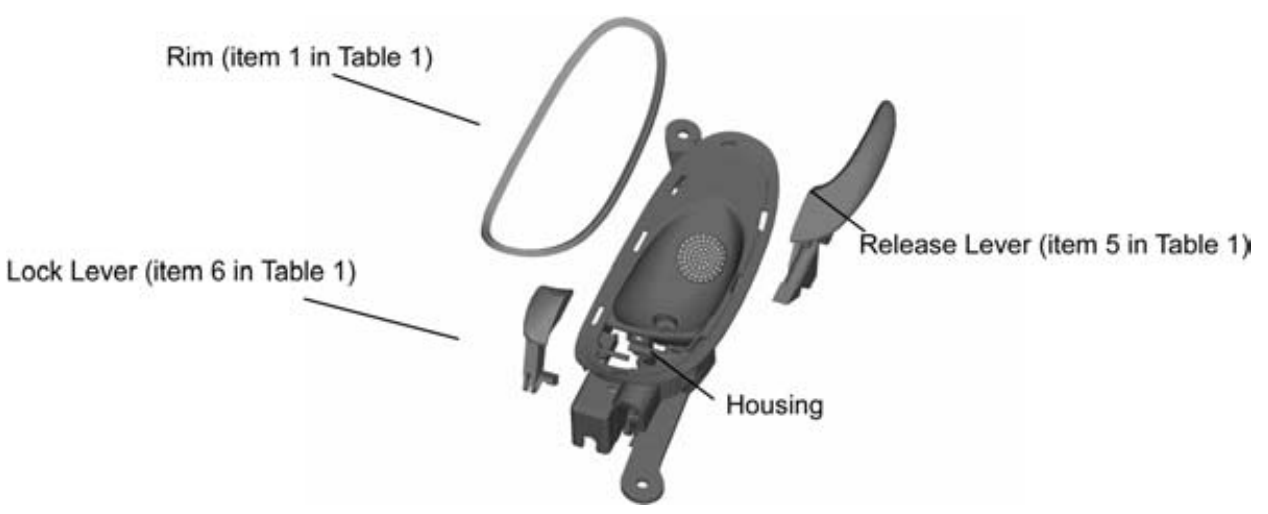

Fig. 8 Exploded image of the four-component redesign idea

Table 3 Disassembly sequence for design idea II

\begin{tabular}{lll}
\hline Step & Process & Reuse or recycle? \\
\hline 1 & Pull out the release lever bolt and remove the release lever & Reuse \\
2 & Similar operation to the above in removing the lock lever & Reuse \\
3 & Unfasten the snap fit between the housing and the rim & Recycle \\
4 & Remove the rim from the housing & Recycle \\
\hline
\end{tabular}




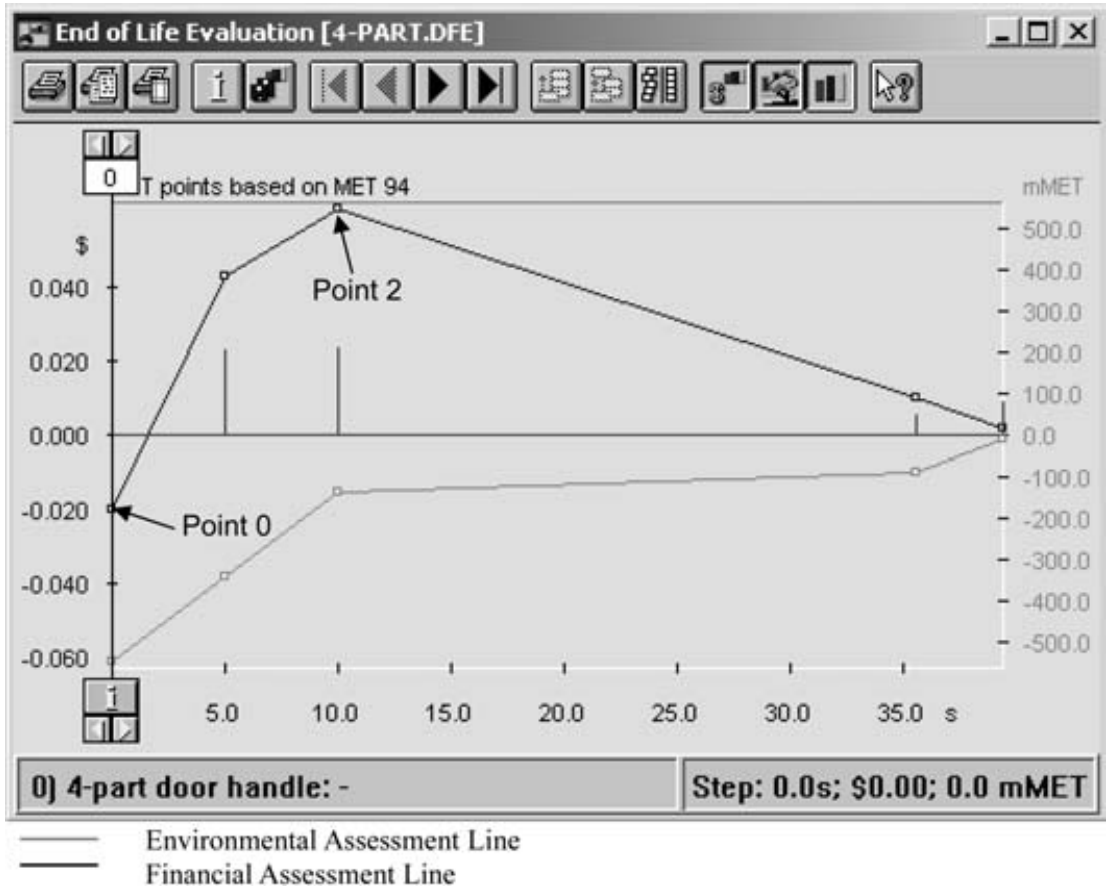

Fig. 9 Boothroyd Dewhurst DFE assessment graph of the four-component redesign idea

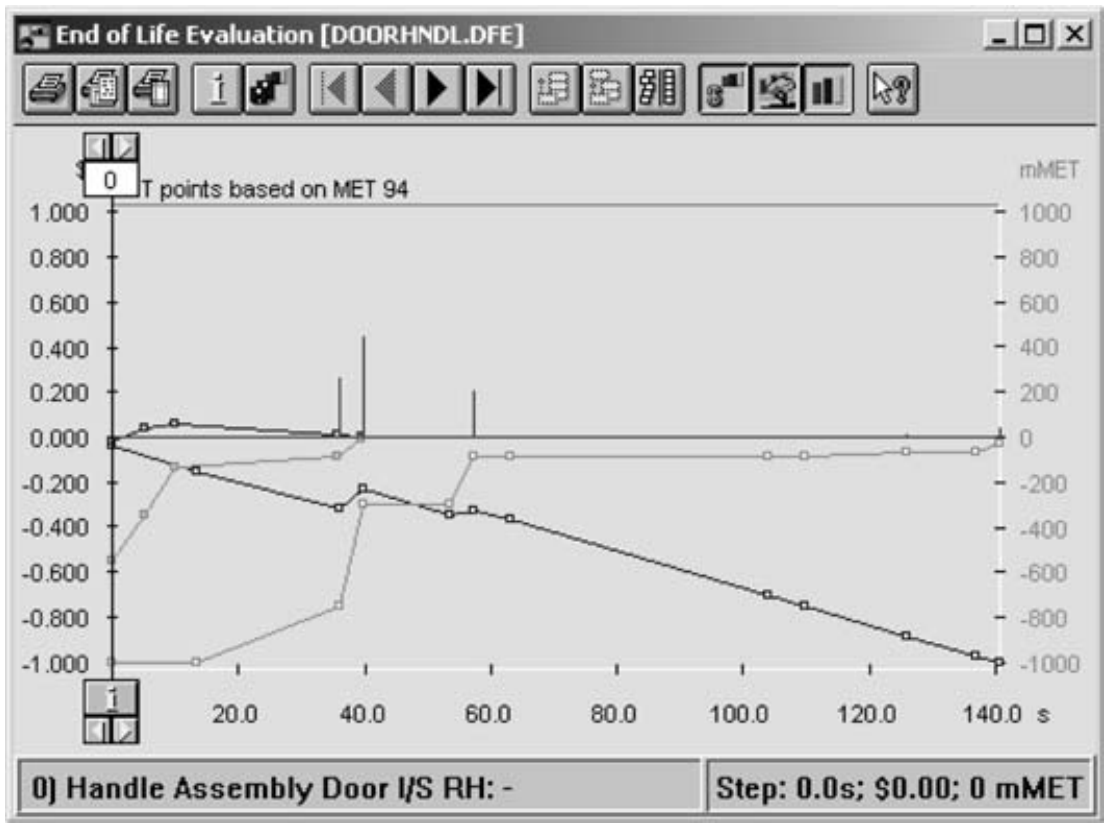

Fig. 10 Financial and environmental comparison graph

times and costs for disassembly. Additionally, where an assembly of parts made by different materials using different processes can be manufactured as a single part from a single product, the potential for recycling is significantly improved.
RM technologies have provided a revolutionary and disruptive set of manufacturing and design solutions in a variety of fields from aerospace to medical. During the work performed for this report, the potential for RM also showed some revolutionary 
and disruptive potential. The design freedoms afforded by the SLS process allowed the door handle assembly to be manufactured as a single unit from a single material and this rendered a DFE analysis of the design impossible. Under normal circumstances, DFE analysis would be used to optimize a design to improve the potential for reuse and recycling, but in this case such an analysis was completely redundant. This finding suggests that designers may begin to ask some fundamentally new questions regarding the design of new products, including the potential to eliminate or significantly reduce assembly and disassembly and also to reduce the range of materials used within a product. These findings have wide implications in terms of environmental take-back issues but may also affect factors such as the range of material sources and production methods adopted in the future. While there are some wide and profound implications to the potential to apply RM in industries such as the automotive industry, there are still many issues that need to be addressed.

The aesthetic quality of the door handles created using SLS would be inadequate for such a component in a production car, which necessitates a second redesign incorporating a number of aesthetic improvements. However, the potential to apply $\mathrm{RM}$ to non-visual components offers a significant opportunity to revolutionize the manufacturing approach adopted by many organizations. Indeed, SLS is now used to make numerous automotive components for Formula 1 applications.

Currently, the cost of RM parts is often prohibitive except in low-volume applications. However, as the technology improves, RM is finding applications in higher volumes for both mass customized and series production, both of which have a significant interest for the automotive sector. It is likely that applications from Formula 1 will soon develop into economically viable options in the luxury car market and then into higher-volume sectors.

In terms of the specific application of $\mathrm{RM}$ to address environmental issues, the key next step will be to evaluate the environmental impact of using RM processes and materials such that these data can be incorporated into DFE and LCA software. Until this is applied, the policy of selecting a 'best fit', for example injection moulding in place of SLS and nylon 6 in place of nylon 12, will render such environmental analyses somewhat vague.

\section{REFERENCES}

1 Wohlers, T. Rapid prototyping tooling and manufacture, Annual State of the Industry Report, Wohlers Associates, USA, 2003.

2 Jacobs, P. F. A brief history of rapid prototyping and manufacturing: the growth years. International Conference on Metal Powder Deposition for Rapid Manufacturing, San Antonio, Texas, 8-10 April 2002, pp. 5-8 (Metal Powder Industries Federation).

3 Dickens, P. An overview of rapid manufacturing. In Proceedings of Time-Compression Technologies Conference, Nottingham, 12-13 October 1999, pp. 119-122.

4 Murphy, M. The future of additive manufacturing. TCT Mag., April 2000, 8(2), 53-58.

5 Hague, R. J., Mansour, S., Saleh, N., and Sun, Z. Design opportunities with rapid manufacturing. In Proceedings of TCT Conference, Manchester, UK, October 2002, 25 pp. [CD-ROM].

6 Zarringhalam, H. and Hopkinson, N. Postprocessing of duraform ${ }^{\mathrm{TM}}$ parts for rapid manufacture. In Proceedings from the 14th SFF Symposium, Austin, Texas, 4-6 August 2003, pp. 596-606.

7 Halliday, I. and Hague, R. The management of rapid manufacturing. TCT Conference, GMEX, Manchester, 16-17 October 2002 (Rapid News Publications plc).

8 Caloud, H., Pietrafitta, M., and Masters, M. Use of SLS technology in direct manufacturing of hearing aids. In Proceedings of SLS Users Group Conference, San Francisco, September 2002.

9 Stocker, M. From rapid prototyping to rapid manufacturing. Auto Technol., 2002, 2(2), 38-40.

10 Kaza, S. Utilising SLA in mass customisation. In Proceedings from the SL User Group Meeting, Cost Mesa, California, March 2002.

11 Fiksel, J. and Wapman, K. How to design for environment and minimize life cycle cost. In IEEE Symposium on Electronics and the Environment, San Francisco, California, May 1994.

12 Huang, G. Q. Design for X: concurrent engineering imperatives, 1996 (Chapman and Hall, London).

13 Ehrenfeld, J. and Lenox, M. Implementing design for environment: a primer, 1997 (Digital Equipment Corporation, Maynard, Massachusetts). 